\title{
МЕЖДУНАРОДНО-ПРАВОВЫЕ И МЕЖДУНАРОДНО-ПОЛИТИЧЕСКИЕ ИССЛЕДОВАНИЯ: ПРОБЛЕМЫ СИНТЕЗА
}

Аннотация: В последние годы как в отечественной, так и в зарубежной международно-правовой науке наблюдается распространение подходов, используемых в политических исследованиях международных отномений. $B$ данной работе дан генезис формирования такой взаимосвязи с конца 1980 гг. Указаны основные причины междисииплинарного синтеза, в т.ч. повышение роли «мягкого» права и распространение механизмов разрешения споров, базирующихся на внутреннем праве основных международных экономических организаиий (ВТО, МВФ, Группа Всемирного банка) и интеграчионных группировок (ЕС, НАФТА, ЕврАзЭС и др). В статье дан обзор основные направления заимствования, в числе которых диагностика существующих международных проблем, их структурирование и поиск международно-правовых механизмов их решения; анализ структуры и функиий, организачионного дизайна существующих международных режимов и институтов; вопросы изменения отдельных принципов международного права и самой природы международного права в целом. По каждому из направлений приведены основные исследования. Сделан вывод о том, что распространение инструментария политической науки в международном праве способствует обогащению последнего, формированию плодотворного междисииплинарного синтеза, позволяющего проводить многогранный анализ международной действительности.

Abstract: In late years both in Russian and foreign international law science faces the spread of approaches, which are used in political studies of international relations. This work analyzes the genesis of this interrelation starting from late 1980s. The author discusses the main causes of interdisciplinary synthesis, including growing role of the "soft law" and spread of conflict resolution mechanisms base upon the internal law of the main international economic organizations (WTO, IMF, World Bank Group) and integration groups (the EU, the NAFTA, the EurAsEC, etc.). The article contains an overview of the main directions of borrowing, including diagnosing the main international problems, their structuring and searching for the international legal mechanisms for their solution, analysis of structure and functions of organization design of the existing international regimes and institutions, as well as international law as a whole. On each of these directions the author provides the key studies. The conclusion is made that spread of instruments of political science in the international law facilitates its enrichment, formation of the fruitful interdisciplinary synthesis, allowing for the multifaceted analysis of international reality.

Ключевые слова: Юриспруденция, международное право, международные отночения, междисииплинарные подход, методы правовых исследований, синтез международного права и международных отноте, мягкое право, международные организачии, международные режимы, глобальное управление.

Keywords: Jurisprudence, international law, international relations, interdisciplinary approach, methods of legal studies, synthesis of international law and international relations, soft law, international organizations, international regimes, global administration.

\section{Отечественные исследования}

отечественных исследованиях вопросом конвергенции международного права и международных отношений занимался видный эксперт в области международных организаций Г.И.Морозов. В его монографии ${ }^{1}$ особая роль уделяется проблеме

\footnotetext{
${ }^{1}$ См. 1) Морозов Г.И. Международное право и международные отношения. Проблемы взаимосвязи / Предисл.: Быкова О.Н.; Ред.: Зайцева О.Г. - М., 1997. - 70 с.; 2) Колосов Ю.М. Роль
}

взаимосвязи и взаимодействия международных отношений и международного права, международному договору как основному институту международных отношений. Отечественные юристы-международники также особо подчеркивают диалектическое единство и взаимодействие внешней политики и международного

международного права в нашей жизни (к выходу в свет брошюры Г.И. Морозова «Международное право и международные отношения (проблемы взаимосвязи)») // Московский журнал международного права. - 1997, № 2. - С. 164-166. 
права². В самом деле, внешняя политика (курс государства в международных отношениях и действия по реализации данного курса) реализуется под влиянием существующего международного права. С другой стороны, международное право развивается под влиянием взаимодействия внешнеполитических курсов различных государств.

Российские специалисты по международным отношениям отмечают необходимость изучения международного права в «более широком синтезированном контексте связей права и мировых политических процессов» ${ }^{3}$. По их мнению, международное право само по себе конфликтно, т.к. предполагает «строгое соблюдение принципов» с одной стороны, и необходимость их развития и модификации согласно текущей международно-политической реальности, с другой стороны. Кроме того, характерной чертой современного этапа развития мировой политической системы является расширение негосударственного взаимодействия, которое не подпадает под действие большинства норм классического международного права. В настоящее время, характеризуя регулятивную компоненту международных отношений, ряд экспертов предпочитает говорить о системе «глобального управления» (англ. global governance), включающей как комплекс норм международного права, так и режимы и институты мирового взаимодействия.

\section{Зарубежные исследования}

В зарубежных исследованиях также отмечается необходимость совместного анализа международнополитической и международно-правовой реальности. Одной из первых работ в этой области является статья К.Аббота ${ }^{4}$, в которой он призывает юристов-международников изучать теорию международных режимов ${ }^{5}$, поскольку, по его мнению, она имеет множество применений в международном праве. Он даже высказался за формирование единой дисциплины, которая была

\footnotetext{
${ }^{2}$ Международное право: учебник / Отв. ред. А.Н.Вылегжанин. М.: Высшее образование, Юрайт-Издат, 2009. - С.44.

${ }^{3}$ Кулагин В.М. Политико-правовое измерение международных отношений и мировой политики. Глава 7 / Современные международные отношения и мировая политика: Учебник/ Отв. ред. А.В.Торкунов. - М.: Просвещение: МГИМО, 2004. - С.164-189.

${ }^{4}$ Abbott K. Modern International Relations Theory: A Prospectus for International Lawyers // Yale Journal of International Law. 1989. - 14: $335-411$.

${ }_{5}^{5}$ Подробнее о теории международных режимов см. Цыганков П.А. Теория международных отношений : учебник. -2-е изд., испр. и доп. - М.: Гардарики, 2007. - С.447-450.
}

бы призвана сократить разрыв, существующий между теорией международных отношений и международным правом. Через несколько лет была опубликована работа А. - М.Слотер ${ }^{6}$, профессора Школы права Гарвардского университета, одного из ведущих в мире сторонников объединения международно-политических и международно-правовых исследований в общих методологических рамках, президента Американского общества международного права в 2002-2004 гг. Фактически, с этого момента (19931994 гг.) в зарубежной научной печати пошел лавинообразный поток работ о взаимосвязи международного права и теории международных отношений.

Свидетельством этого являются результаты контент-анализа, проведенного А. - М.Слотер и ее коллегами в декабре 1997 г. на основе статистического исследования перекрестного цитирования политологической литературы юристами-международниками в международной базе данных LexisNexis?. Например, ключевая монография по международным режимам Р.Кохейна, вышедшая в 1984 г. ${ }^{8}$ в исследуемый период (1990-1997 гг.) цитировалась юристами 41 раз, причем 39 из них - после 1993 г. Аналогично, термин «теория режимов» использовался в юридических работах с 1990 г 44 раза, хотя в период 1990-1994 гг. всего 6 раз. «Институционализм» - 40 раз после 1990 г. и 6 раз в 1990-1994 гг. Упоминавшая статья К.Аббота 1989 г. ${ }^{9}$ цитировалась 1991 г., из них 34 - после 1995 г., статья А. - М.Слотер 1993 г. ${ }^{10}$ цитировалась 56 раз, из них 38 - после 1995 г. и 29 - после 1996 г. Политологический термин «реализм» цитировался в юридической литературе 13 раз, из них 10 - после 1994 г.

В 1996-1997 гг. два раза подряд конкурс работ молодых юристов-международников им. Франсиса

\footnotetext{
${ }^{6}$ Slaughter A. - M. International Law and International Relations Theory: A Dual Agenda // American Journal of International Law. 1993. - 87: 205-239. Также см. Slaughter A. - M. Liberal International Relations Theory and International Economic Law // American Journal of International Law, 1995. - 10: 717-731.

${ }^{7}$ Slaughter A. - M., Tulumello A., Wood S. International Law and International Relations Theory: A New Generation of Interdisciplinary Scholarship // American Journal of International Law. 1998. - 92: 367-397.

${ }^{8}$ Keohane R. After Hegemony: Cooperation and Discord in the World Political Economy. - Princeton University Press, 1984.

${ }^{9}$ Abbott K. Modern International Relations Theory: A Prospectus for International Lawyers // Yale Journal of International Law. 1989. - 14: 335-411.

${ }^{10}$ Slaughter A. - M. International Law and International Relations Theory: A Dual Agenda // American Journal of International Law. 1993. - 87: 205-239.
} 


\section{Право и политика $8(176) \cdot 2014$}

Деака (Francis Deák Prize), проводимый ежегодно Американским журналом международного права, выигрывали авторы междисциплинарных работ (международные отношения - международное право) ${ }^{11}$. В опубликованных в это время в Гарвардском журнале международного права статьях, посвященных праву международных договоров ${ }^{12}$, также делался акцент на необходимости междисциплинарного синтеза.

Ключевой вехой в развитии взаимосвязи международных отношений и международного права стала программная лекция ведущего специалиста-международника Р.Кохейна в Йельской школе права в 1996 г. на тему «Международные отношения и международное право: две перспективы» ${ }^{13}$. В 2000 г. Гаагская академия международного права в рамках юбилейных лекций провела курс, посвященный синтезу международного права и международных отношений.

С 2005 г. Факультет права и Школа международных отношений Мунка (Munk School of Global Affairs) Университета Торонто (Канада) издают «Журнал международного права и международных отношений» (The Journal of International Law and International Relations) ${ }^{14}$. Развитию синтеза двух наук в немалой степени способствовало и то, что такие издания, как «Журнал по переговорам» («Negotiation Journal»), «Журнал по разрешению конфликтов» («Journal of Conflict Resolution»), «Международная организация» («International Organization») изначально носили междисциплинарный характер. В них международные проблемы анализировались как с политологической, экономической, так и международно-правовой точки зрения.

Плодотворный синтез двух наук активно продолжился и во второй половине $2000-$ х годов ${ }^{15}$.

${ }^{11}$ CM. 1) Benvenisti E. Collective Action in the Utilisation of Shared Freshwater: The Challenges of International Water Resources Law // American Journal of International Law. 1996. - 90: 384-415; 2) Brunnée J., Toope S. Environmental Security and Freshwater Resources: Ecosystem Regime Building // American Journal of International Law. 1997. - 91: 26-59.

${ }^{12}$ CM. 1) Setear J. An Iterative Perspective on Treaties: A Synthesis of International Relations Theory and International Law // Harvard International Law Journal. 1996. - 37: 139-229; 2) Byers M. Taking the Law out of International Law: A Critique of the Iterative Perspective // Harvard International Law Journal. 1997. - 38: 201-205.

${ }^{13}$ Keohane $R$. International Relations and International Law: Two Optics // Harvard International Law Journal, 1997. - 38: 487-502.

${ }^{14} \mathrm{C}$. официальный сайт «Журнала международного права и международных отношений» - http://www.jilir.org/

${ }^{15}$ См., например, Hathaway O., Koh H., eds. Foundations of International Law and Politics. - New York: Foundation Press, 2005; Rochester M. Between Peril and Promise: The Politics of International
Наиболее современный обзор литературы по использованию методов международно-политической науки в международном праве содержится в работе Э.Хафнер-Бертон и др. ${ }^{16}$

\section{Причины междисциплинарного синтеза}

Как представляется, основных причин синтеза международно-правовой и международно-политической науки в зарубежных исследованиях несколько. После распада СССР и усиления однополярных тенденций роль международного права как регулятора международных отношений несколько ослабла, как и влияние институтов системы ООН. На этом фоне стало возрастать значение системы «мягкого» права, рекомендательные нормы которого во внутренней политике различных государств стали активно продвигать многочисленные неправительственные организации. Помимо этого активное распространение получили механизмы разрешения споров, базирующиеся на внутреннем праве основных международных экономических организаций (ВТО, МВФ, Группа Всемирного банка) и интеграционных группировок (ЕС, НАФТА, ЕврАзЭС и др). Данные структуры обладают сегодня настоящей квазисудебной властью, основанной на компетенции самостоятельно толковать свои учредительные документы ${ }^{17}$.

Американские специалисты-международники после периода однополярности 1990-х гг. и намеренного ослабления системы международного права со стороны мирового гегемона, с начала 2000-х гг. предпринимают попытку легализовать т.н. международные режимы, включающие уже помимо классических норм международного права многочисленные нормы «мягкого права». Данной теме был посвящен специальный номер журнала «Международная организация» (International Organization), вышедший в 2000 году и содержащий более 10 публикаций по вопросам формирования международных режимов в области разрешения конфликтов, экономической интеграции, международных валютно-

Law - Washington, DC: CQ Press, 2006; Simmons B., Steinberg R., eds. International Law and International Relations. - New York: Cambridge University Press, 2006; Armstrong D., Farrell Th., Lambert H. International Law and International Relations. - Cambridge: Cambridge University Press, 2007; Biersteker T., Spiro P., Sriram Ch., Raffo V., eds. International Law and International Relations: Bridging Theory and Practice. - London: Routledge, 2007.

${ }^{16}$ Hafner-Burton E., Victor D., Lupu Y. Political Science Research on International Law: The State of the Field // American Journal of International Law, 2012. - Vol. 106, No. 1: 47-97.

${ }^{17}$ См. Дегтерев Д.А. Экономическая дипломатия: экономика, политика, право. - М.: МГИМО, Навона, 2010. - С.24. 
кредитных отношениях, торговой либерализации и защиты прав человека ${ }^{18}$. Впоследствии данный выпуск журнала был издан в качестве отдельной монографии ${ }^{19}$.

Не разделяя скептицизма американских исследователей по отношению к классическому международному праву, вместе с тем представляется обоснованным анализировать международные отношения как социальный контекст, в котором формируется международное право. Как и во внутригосударственном праве, необходимо рассматривать международно-правовые отношения в комплексе, изучая в т.ч. реальное поведение субъектов правоотношения (как правомерное, так и противоправное), объективные элементы социального бытия и различные субъективные, мировоззренческие факторы.

\section{Основные направления заимствования}

Можно выделить несколько основных направлений заимствования международно-политических концепций юристами-международниками:

1) диагностика существующих международных проблем, их структурирование и поиск международноправовых механизмов их решения;

2) анализ структуры и функций, организационного дизайна существующих международных режимов и институтов;

3) вопросы изменения отдельных принципов международного права и самой природы международного права в целом ${ }^{20}$.

Благодаря заимствованиям первого типа такие теоретические конструкты как проблема коллективных действий, «проблема безбилетника», провалы рынка, «дилемма заключенного» стали широко использоваться в международно-правовых исследованиях. Именно они позволяют структурировать существующую международную проблему, выявить интересы всех вовлеченных сторон и предложить соответствующую юридическую конструкцию.

Одно из основных направлений применения данных концепций - международное торговое и международное экологическое право. В частности, Э.Бенвенисти

\footnotetext{
${ }^{18}$ Legalization and World Politics (Special Issue) // International Organization. - 2000. - Vol. 54, No 3.

${ }^{19}$ Goldstein J., Kahler M., Keohane R., Slaughter A. - M., eds. Legalization and World Politics. - Cambridge: MIT Press, 2001.

${ }^{20}$ Slaughter A. - M., Tulumello A., Wood S. International Law and International Relations Theory: A New Generation of Interdisciplinary Scholarship // American Journal of International Law. 1998. - 92: 367-397.
}

относит управление запасами пресной воды к классической проблеме коллективных действий, исходя из чего предлагает свои подходы к международно-правовому урегулированию данной проблемы ${ }^{21}$. Р.Шмидт использует положение Р.Путнама о двухуровневом анализе переговорного процесса для моделирования переговоров между США и Канадой по вопросу ограничения отлова тихоокеанского лосося ${ }^{22}$. Схожую концепцию использует и М. Монтанья-Мора при анализе разногласий между США и ЕС в ходе Уругвайского раунда торговых переговоров по вопросам субсидирования сельскохозяйственного экспорта ${ }^{23}$.

Теория и методология анализа международных отношений нашли широкое применение в международно-правовых исследованиях по вопросам израильского-палестинского конфликта, проблематике международного терроризма и целому ряду других вопросов - от антимонопольного законодательства до торговых войн ${ }^{24}$.

В рамках второго направления заимствований методологии международно-политических исследований школой международного права инструментарий и методы политической науки применяются в контексте институциональной экономики, теории принятия решений, социальной психологии, анализа организационного дизайна и компетенций международных институтов. Одним из первопроходцев в рамках данного направления является К.Аббот, исследовавший неко-

${ }^{21}$ Benvenisti E. Collective Action in the Utilization of Shared Freshwa-
ter: The Challenges of International Water Resources Law // American
Journal of International Law, 1996. - 90: 384-415
${ }^{22}$ Schmidt R. International Negotiations Paralyzed by Domestic Poli-
tics: Two-Level Game Theory and the Problem of the Pacific Salmon
Commission // Environmental Law, 1996. - 26: 95-139.
${ }^{23}$ Montana-Mora M. International Law and International Relations
Cheek to Cheek: An International Law/International Relations Per-
spective on the US/EC Agricultural Export Subsidies Dispute // North
Carolina Journal of International Law and Commercial Regulation, Carolina Journa

См. например, Macey J. Chicken Wars as a Prisoner's Dilemma: What's in a Game? // Notre Dame Law Review, 1989. - 64: 447-450 (review of Conybeare J., Trade Wars: The Theory and Practice of International Commercial Rivalry); Colombatto E., Macey J. A Public Choice Model of International Economic Cooperation and the Decline of the Nation State // Cardozo Law Review, 1996. - 18: 925-956; Ayaz Sh. A Theoretic Approach to Transnational Terrorism // Georgetown Law Journal, 1992. - Vol. 80: 2131-2174; Hirsch M. The Future Negotiations over Jerusalem, Strategical Factors and Game Theory // Catholic University Law Review, 1996. - 45: 699-722; Mock W. Game Theory, Signaling and International Legal Regulations // George Washington Journal of International Law \& Economics, 1992. - 26: 33-66; Waller S. Neo-Realism and the International Harmonization of Law: Lessons from Antitrust // University of Kansas Law Review, 1994. - 42: 557-604. 


\section{Право и политика $8(176) \cdot 2014$}

торые аспекты соблюдения международных режимов нераспространения ${ }^{25}$, права международной торговли ${ }^{26}$, предотвращения преступлений против человечества ${ }^{27}$, а также общих принципов применения концептов институционализма в международном праве ${ }^{28}$.

У.Эйсив анализирует влияние некоторых статей Договора о всеобъемлющем запрещении ядерных испытаний на формирование соответствующего международного режима в соответствии с предпосылками институционализма ${ }^{29}$. Дж.Колбэрн использует теорию режимов для объяснения некоторых аспектов управления трансграничными рыбными запасами и запасами далеко мигрирующих рыб ${ }^{30}$. Д.Фидлер и Б.Плоткин анализируют, насколько новые регулирующие нормы Всемирной организации здравоохранения способствуют созданию эффективного режима в понимании институционалистов ${ }^{31}$. Общие вопросы институционального дизайна международных режимов рассмотрены в работе Г.Даунса и др. ${ }^{32}$, а анализ режимов предотвращения загрязнения нефтепродуктами приведен в работе Р.Митчела ${ }^{33}$.

Изучение особенностей функционирования международных институтов в контексте международного права получило столь широкое распространение, что в

${ }^{25}$ Abbott K. «Trust But Verify»: The Production of Information in Arms Control Treaties and Other International Agreements // Cornell International Law Journal, 1993. - 26: 1-58.

${ }^{26}$ Abbott $K$. The Trading Nation's Dilemma: The Functions of the Law of International Trade // Harvard International Law Journal, 1985. 26: 501-532.

${ }^{27}$ Abbott K. International Relations Theory, International Law and the Regime Governing Atrocities in Internal Conflicts // American Journal of International Law, 1999. - Vol. 93 (2): 361-379.

${ }^{28}$ Abbott K. Toward a Richer Institutionalism for International Law and Policy // Journal of International Law and International Relations, 2006. $-1: 9$.

${ }^{29}$ Aceves $W$. Institutionalist Theory and International Legal Scholarship // American University Journal of International Law, 1997. - 12 (2): 227-266.

${ }^{30}$ Colburn J. Note, Turbot Wars: Straddling Stocks, Regime Theory, and a New U.N. Agreement // Florida State University Journal of Transnational Law \& Policy, 1997. - 6: 323-366.

${ }^{31}$ Fidler D. Mission Impossible? International Law and Infectious Diseases // Temple International and Comparative Law Journal, 1996. - 10: 493-502; Plotkin B. Mission Possible: The Future of the International Health Regulations // Florida State University Journal of Transnational Law \& Policy, 1997. - 6: 503.

${ }^{32}$ Downs G., Rocke D., Barsoom P. The Transformational Model of International Regime Design: Triumph of Hope or Experience? // Columbia Journal of Transnational Law, 2000. - 38: 465-514.

${ }^{33}$ Mitchell R. Regime Design Matters: International Oil Pollution and Treaty Compliance // International Organization, 1994. - Vol. 48 (3): 425-458. зарубежных исследованиях выделяют даже т.н. «управленческую школу» («managerial school») международного права. Основателем данной школы принято считать А.Чейса и А.Чейс ${ }^{34}$. По их мнению, несоблюдение международных соглашений не связано с недостатком принудительного применения права или санкций, а с несовершенством формулировок международных договоров, недостаточным обменом информации в рамках уставливаемых режимов, несоответствием положений международных договоров внутреннему законодательству стран-подписантов.

Специфика процедур принятия решения в международных организациях рассмотрена в работах двух представителей Мичиганского университета - второго по значению в США (и, пожалуй, в мире) центра по экономическому анализу права (после Чикаго) Г.Тсебелиса ${ }^{35}$ и Б. Буено де Мескито ${ }^{36}$.

Важный вклад в развитие теории институционализма в контексте международного права внесла Б.Коременос, рассматривающая дизайн международных организаций, регулирующих разные отрасли международного права ${ }^{37}$. Автор данного исследования также внес посильный вклад в данное направление исследований, опубликовав статью по институциональному дизайну международного режима содействия развитию ${ }^{38}$.

${ }^{34}$ Chayes A., Chayes A. On Compliance // International Organization, 1993. - 47: 175-205; Chayes A., Chayes A. The New Sovereignty: Compliance with International Regulatory Agreements. - Cambridge, Mass.: Harvard University Press, 1995.

${ }^{35}$ Tsebelis G., Yataganas X. The Treaty of Nice, the Convention Proposal, and the Treaty Establishing a Constitution for Europe: A Veto Players Analysis // European Constitutional Law Review, 2005. - 1 (3): 429-451; Tsebelis G., Garrett G. The Institutional Determinants of Intergovernmentalism and Supranationalism in the EU // International Organization, 2001. - 55(2): 357-390; Tsebelis G., Garrett G. Agenda Setting, Vetoes, and the EU's Codecision Procedure // Journal of Legislative Studies, 1997. - 3: 74-92.

${ }^{36}$ Bueno de Mesquito B., Smith A. The Pernicious Consequences of UN Security Council Membership // Journal of Conflict Resolution, 2010. - Vol. 54 (5): 667-686.

${ }^{37}$ Koremenos B. When, What, and Why Do States Choose to Delegate?.// Law and Contemporary Problems, 2008. - Vol. 71 (1): 151-192; Koremenos B. If Only Half of International Agreements Have Dispute Resolution Provisions, Which Half Needs Explaining? // Journal of Legal Studies, 2007. - 36: 189-212; Koremenos B. Contracting around International Uncertainty. American Political Science Review, 2005. 99: 549-565; Koremenos B., Lipson Ch., Snidal D. The Rational Design of International Institutions // International Organization, 2001. - 55 (4): 761-799; Koremenos B. Loosening the Ties That Bind: A Learning Model of Agreement Flexibility. International Organization, 2001. 55: 289-325.

38 Дегтерев Д.А. Теоретико-игровой анализ режимов оказания содействия международному развитию // Вестник МГИМО-Университета, 2011. - №5. - С.59-66. 
DOI: $10.7256 / 1811-9018.2014 .8 .7539$

При цитировании этой статьи сноска на dоі обязательна

Международное право в XXI веке

В рамках третьего направления заимствования появился целый ряд работ о том, каким образом меняется сама природа международного права в результате формирования новых международных институтов, насколько соблюдаются нормы международного права и почему это происходит или не происходит. Одна из первых работ в этой сфере принадлежит Ф.Абботу ${ }^{39}$, который в дальнейшем рассматривал вопросы становления международного режима частной собственности ${ }^{40}$ и влияния права ВТО на глобальное экономическое развитие $^{41}$. Вопросы влияния норм международного права на эффективность разрешения международных споров рассмотрены в работах Р.Брюстера ${ }^{42}$, Т.Гинсбурга и др ${ }^{43}$. В статьях О.Хатэуэйя ${ }^{44}$, К.Раустиала ${ }^{45}$, Р.Скотта ${ }^{46}$, Дж.Сэтера ${ }^{47}$, Е.Свейна ${ }^{48}$ и А.Сикса ${ }^{49}$ анализируется влияния норм международного права на изменение социального контекста.

Отдельно стоит отметить представителей Чикагской школы экономики и права Дж.Голдсмита и Э.Познера, которые в своих ранних работах практически отрицали существование эффективного международного права ${ }^{50}$,

${ }^{39}$ Abbott F. Modern International Relations Theory: A Prospectus for International Lawyers. Yale Journal of International Law, 1989. 14: 335-411.

${ }^{40}$ Abbott F. Commentary: The International Intellectual Property Order Enters the Twenty-First Century. Vanderbilt Journal of Transnational Law, 1996. 29: 471-479.

${ }^{41}$ Abbott F. The WTO TRIPs Agreement and Global Economic Development. Chicago-Kent Law Review, 1996. 72: 385-405.

${ }^{42}$ Brewster R. Rule-Based Dispute Resolution in International Trade Law. Virginia Law Review, 2006. 92: 251-288.

${ }^{43}$ Ginsburg T., McAdams R. Adjudicating in Anarchy: An Expressive Theory of International Dispute Resolution. William and Mary Law Review, 2004. 45: 1229-1339.

${ }^{44}$ Hathaway $O$. Do Human Rights Treaties Make a Difference? Yale Law Journal, 2002. 111: 1935-2042.

${ }^{45}$ Raustiala K. Form and Substance in International Agreements. American Journal of International Law, 2005. 99: 581-614.

${ }^{46}$ Scott R., Stephan P. The Limits of Leviathan: Contract Theory and the Enforcement of International Law. 2006. New York: Cambridge University Press.

${ }^{47}$ Setear J. Responses to Breach of a Treaty and Rationalist International Relations Theory: The Rules of Release and Remediation in the Law of Treaties and the Law of State Responsibility. Virginia Law Review, 1997. 83: 1-126.

${ }^{48}$ Swaine E. Unsigning. Stanford Law Review, 2003. 55: 2061-2089.

${ }^{49}$ Sykes A. Protectionism as a "Safeguard": A Positive Analysis of the GATT "Escape Clause" with Normative Speculations. University of Chicago Law Review, 1991. 58: 255-303.

${ }^{50}$ Goldsmith J., Posner E. The Limits of International Law. Oxford University Press, 2005; Goldsmith J., Posner E. A Theory of Customary International Law. University of Chicago Law Review, 1999. 66: чем заслужили справедливую критику со стороны классической школы юристов-международников ${ }^{51}$.

$$
* * *
$$

Представляется, что распространение инструментария политической науки в международном праве способствует обогащению последнего, формированию плодотворного междисциплинарного синтеза, позволяющего проводить многогранный анализ международной действительности.

\section{Библиография:}

1. Дегтерев Д.А. Теоретико-игровой анализ режимов оказания содействия международному развитию // Вестник МГИМО-Университета, 2011. - №5. C. 59-66.

2. Дегтерев Д.А. Экономическая дипломатия: экономика, политика, право. - М.: МГИМО, Навона, 2010.

3. Колосов Ю.М. Роль международного права в нашей жизни (к выходу в свет брошюры Г.И. Морозова «Международное право и международные отношения (проблемы взаимосвязи)») // Московский журнал международного права. - 1997, № 2. - С. 164-166.

4. Кулагин В.М. Политико-правовое измерение международных отношений и мировой политики. Глава 7 / Современные международные отношения и мировая политика: Учебник/ Отв. ред. А.В.Торкунов. - М.: Просвещение: МГИМО, 2004. - C.164-189.

5. Международное право: учебник / Отв. ред. А.Н.Вылегжанин. - М.: Высшее образование, Юрайт-Издат, 2009.

6. Морозов Г.И. Международное право и международные отношения. Проблемы взаимосвязи / Предисл.: Быкова О.Н.; Ред.: Зайцева О.Г. - М., 1997. - 70 c.

7. Цыганков П.А. Теория международных отношений: учебник. - 2-е изд., испр. и доп. - М.: Гардарики, 2007.

1113-1177; Goldsmith J., Posner E. Understanding the Resemblance between Modern and Traditional Customary International Law. Virginia Journal of International Law, 2000. 40: 639-672.

${ }^{51}$ Aaken A. To Do Away with International Law? Some Limits to 'The Limits of International Law' // European Journal of International Law, 2006. - 17 (1): 289-308. 


\section{Право и политика $8(176) \cdot 2014$}

8. Aaken A. To Do Away with International Law? Some Limits to 'The Limits of International Law' // European Journal of International Law, 2006. - 17 (1): 289-308.

9. Abbott F. Commentary: The International Intellectual Property Order Enters the Twenty-First Century. Vanderbilt Journal of Transnational Law, 1996. 29: 471-479.

10. Abbott F. Modern International Relations Theory: A Prospectus for International Lawyers. Yale Journal of International Law, 1989. 14: 335-411.

11. Abbott F. The WTO TRIPs Agreement and Global Economic Development. Chicago-Kent Law Review, 1996. 72: 385-405.

12. Abbott K. «Trust But Verify»: The Production of Information in Arms Control Treaties and Other International Agreements // Cornell International Law Journal, 1993. - 26: 1-58.

13. Abbott K. International Relations Theory, International Law and the Regime Governing Atrocities in Internal Conflicts // American Journal of International Law, 1999. - Vol. 93 (2): 361-379.

14. Abbott K. Modern International Relations Theory: A Prospectus for International Lawyers // Yale Journal of International Law. 1989. - 14: 335-411.

15. Abbott K. The Trading Nation's Dilemma: The Functions of the Law of International Trade // Harvard International Law Journal, 1985. - 26: 501-532.

16. Abbott K. Toward a Richer Institutionalism for International Law and Policy // Journal of International Law and International Relations, 2006. - 1: 9.

17. Aceves W. Institutionalist Theory and International Legal Scholarship // American University Journal of International Law, 1997. - 12 (2): 227-266.

18. Armstrong D., Farrell Th., Lambert H. International Law and International Relations. - Cambridge: Cambridge University Press, 2007.

19. Ayaz Sh. A Theoretic Approach to Transnational Terrorism // Georgetown Law Journal, 1992. - Vol. 80: 2131-2174.

20. Benvenisti E. Collective Action in the Utilization of Shared Freshwater: The Challenges of International Water Resources Law // American Journal of International Law, 1996. - 90: 384-415

21. Biersteker T., Spiro P., Sriram Ch., Raffo V., eds. International Law and International Relations: Bridging Theory and Practice. - London: Routledge, 2007.

22. Brewster R. Rule-Based Dispute Resolution in International Trade Law. Virginia Law Review, 2006. 92: $251-288$.
23. Brunnée J., Toope S. Environmental Security and Freshwater Resources: Ecosystem Regime Building // American Journal of International Law. 1997. -91:26-59.

24. Bueno de Mesquito B., Smith A. The Pernicious Consequences of UN Security Council Membership // Journal of Conflict Resolution, 2010. - Vol. 54 (5): 667-686.

25. Byers M. Taking the Law out of International Law: A Critique of the Iterative Perspective // Harvard International Law Journal. 1997. - 38: 201-205.

26. Chayes A., Chayes A. On Compliance // International Organization, 1993. - 47: 175-205.

27. Chayes A., Chayes A. The New Sovereignty: Compliance with International Regulatory Agreements. - Cambridge, Mass.: Harvard University Press, 1995.

28. Colburn J. Note, Turbot Wars: Straddling Stocks, Regime Theory, and a New U.N. Agreement // Florida State University Journal of Transnational Law \& Policy, 1997. - 6: 323-366.

29. Colombatto E., Macey J. A Public Choice Model of International Economic Cooperation and the Decline of the Nation State // Cardozo Law Review, 1996. - 18: 925-956.

30. Downs G., Rocke D., Barsoom P. The Transformational Model of International Regime Design: Triumph of Hope or Experience? // Columbia Journal of Transnational Law, 2000. - 38: 465-514.

31. Fidler D. Mission Impossible? International Law and Infectious Diseases // Temple International and Comparative Law Journal, 1996. - 10: 493-502.

32. Ginsburg T., McAdams R. Adjudicating in Anarchy: An Expressive Theory of International Dispute Resolution. William and Mary Law Review, 2004. 45: 1229-1339.

33. Goldsmith J., Posner E. A Theory of Customary International Law. University of Chicago Law Review, 1999. 66: 1113-1177.

34. Goldsmith J., Posner E. The Limits of International Law. Oxford University Press, 2005.

35. Goldsmith J., Posner E. Understanding the Resemblance between Modern and Traditional Customary International Law. Virginia Journal of International Law, 2000. 40: 639-672.

36. Goldstein J., Kahler M., Keohane R., Slaughter A. M., eds. Legalization and World Politics. - Cambridge: MIT Press, 2001.

37. Hafner-Burton E., Victor D., Lupu Y. Political Science Research on International Law: The State of the Field // American Journal of International Law, 2012. Vol. 106, No. 1: 47-97. 
38. Hathaway O. Do Human Rights Treaties Make a Difference? Yale Law Journal, 2002. 111: 1935-2042.

39. Hathaway O., Koh H., eds. Foundations of International Law and Politics. - New York: Foundation Press, 2005.

40. Hirsch M. The Future Negotiations over Jerusalem, Strategical Factors and Game Theory // Catholic University Law Review, 1996. - 45: 699-722;

41. Keohane R. After Hegemony: Cooperation and Discord in the World Political Economy. - Princeton University Press, 1984.

42. Keohane R. International Relations and International Law: Two Optics // Harvard International Law Journal, 1997. - 38: 487-502.

43. Koremenos B. Contracting around International Uncertainty. American Political Science Review, 2005. 99: 549-565.

44. Koremenos B. If Only Half of International Agreements Have Dispute Resolution Provisions, Which Half Needs Explaining? // Journal of Legal Studies, 2007. - 36: 189-212.

45. Koremenos B. Loosening the Ties That Bind: A Learning Model of Agreement Flexibility. International Organization, 2001. 55: 289-325.

46. Koremenos B. When, What, and Why Do States Choose to Delegate?.// Law and Contemporary Problems, 2008. - Vol. 71 (1): 151-192.

47. Koremenos B., Lipson Ch., Snidal D. The Rational Design of International Institutions // International Organization, 2001. - 55 (4): 761-799.

48. Legalization and World Politics (Special Issue) // International Organization. - 2000. - Vol. 54, No 3.

49. Macey J. Chicken Wars as a Prisoner's Dilemma: What's in a Game? // Notre Dame Law Review, 1989. - 64: 447-450 (review of Conybeare J., Trade Wars: The Theory and Practice of International Commercial Rivalry)

50. Mitchell R. Regime Design Matters: International Oil Pollution and Treaty Compliance // International Organization, 1994. - Vol. 48 (3): 425-458.

51. Mock W. Game Theory, Signaling and International Legal Regulations // George Washington Journal of International Law \& Economics, 1992. - 26: 33-66.

52. Montana-Mora M. International Law and International Relations Cheek to Cheek: An International Law/ International Relations Perspective on the US/ EC Agricultural Export Subsidies Dispute // North Carolina Journal of International Law and Commercial Regulation, 1993. - 19: 1.

53. Plotkin B. Mission Possible: The Future of the International Health Regulations // Florida State
University Journal of Transnational Law \& Policy, 1997. - 6: 503

54. Raustiala K. Form and Substance in International Agreements. American Journal of International Law, 2005. 99: 581-614.

55. Rochester M. Between Peril and Promise: The Politics of International Law - Washington, DC: CQ Press, 2006.

56. Schmidt R. International Negotiations Paralyzed by Domestic Politics: Two-Level Game Theory and the Problem of the Pacific Salmon Commission // Environmental Law, 1996. - 26: 95-139.

57. Scott R., Stephan P. The Limits of Leviathan: Contract Theory and the Enforcement of International Law. 2006. New York: Cambridge University Press.

58. Setear J. An Iterative Perspective on Treaties: A Synthesis of International Relations Theory and International Law // Harvard International Law Journal. 1996. - 37: 139-229.

59. Setear J. Responses to Breach of a Treaty and Rationalist International Relations Theory: The Rules of Release and Remediation in the Law of Treaties and the Law of State Responsibility. Virginia Law Review, 1997. 83: 1-126.

60. Simmons B., Steinberg R., eds. International Law and International Relations. - New York: Cambridge University Press, 2006.

61. Slaughter A. - M. International Law and International Relations Theory: A Dual Agenda // American Journal of International Law. 1993. - 87: 205-239.

62. Slaughter A. - M. Liberal International Relations Theory and International Economic Law // American Journal of International Law, 1995. - 10: 717-731.

63. Slaughter A. - M., Tulumello A., Wood S. International Law and International Relations Theory: A New Generation of Interdisciplinary Scholarship // American Journal of International Law. 1998. - 92: 367-397.

64. Swaine E. Unsigning. Stanford Law Review, 2003. 55: 2061-2089.

65. Sykes A. Protectionism as a "Safeguard": A Positive Analysis of the GATT "Escape Clause" with Normative Speculations. University of Chicago Law Review, 1991. 58: 255-303.

66. Tsebelis G., Garrett G. Agenda Setting, Vetoes, and the EU's Codecision Procedure // Journal of Legislative Studies, 1997. - 3: 74-92.

67. Tsebelis G., Garrett G. The Institutional Determinants of Intergovernmentalism and Supranationalism in the EU // International Organization, 2001. - 55(2): 357-390. 


\section{Право и политика 8 (176) $\bullet 2014$}

68. Tsebelis G., Yataganas X. The Treaty of Nice, the Convention Proposal, and the Treaty Establishing a Constitution for Europe: A Veto Players Analysis // European Constitutional Law Review, 2005. - 1 (3): 429-451.

69. Waller S. Neo-Realism and the International Harmonization of Law: Lessons from Antitrust // University of Kansas Law Review, 1994. - 42: 557-604.

\section{References (transliteration):}

1. Degterev D.A. Teoretiko-igrovoi analiz rezhimov okazaniya sodeistviya mezhdunarodnomu razvitiyu // Vestnik MGIMO-Universiteta, 2011. - №5. - S.59-66.

2. Degterev D.A. Ekonomicheskaya diplomatiya: ekonomika, politika, pravo. - M.: MGIMO, Navona, 2010.

3. Kolosov Yu.M. Rol' mezhdunarodnogo prava v nashei zhizni (k vykhodu v svet broshyury G.I. Morozova "Mezhdunarodnoe pravo i mezhdunarodnye otnosheniya (problemy vzaimosvyazi)") // Moskovskii zhurnal mezhdunarodnogo prava. - 1997, № 2. - S. 164-166.

4. Kulagin V.M. Politiko-pravovoe izmerenie mezhdunarodnykh otnoshenii i mirovoi politiki. Glava 7 / Sovremennye mezhdunarodnye otnosheniya i mirovaya politika: Uchebnik/ Otv. red. A.V.Torkunov. - M.: Prosveshchenie: MGIMO, 2004. - S.164-189.

5. Morozov G.I. Mezhdunarodnoe pravo i mezhdunarodnye otnosheniya. Problemy vzaimosvyazi / Predisl.: Bykova O.N.; Red.: Zaitseva O.G. - M., 1997. - 70 c.

6. Tsygankov P.A. Teoriya mezhdunarodnykh otnoshenii : uchebnik. -2-e izd., ispr. i dop.-M.: Gardariki, 2007.

7. Aaken A. To Do Away with International Law? Some Limits to 'The Limits of International Law' // European Journal of International Law, 2006. - 17 (1): 289-308.

8. Abbott F. Commentary: The International Intellectual Property Order Enters the Twenty-First Century. Vanderbilt Journal of Transnational Law, 1996. 29: 471-479.

9. Abbott F. Modern International Relations Theory: A Prospectus for International Lawyers. Yale Journal of International Law, 1989. 14: 335-411.

10. Abbott F. The WTO TRIPs Agreement and Global Economic Development. Chicago-Kent Law Review, 1996. 72: 385-405.

11. Abbott K. «Trust But Verify»: The Production of Information in Arms Control Treaties and Other International Agreements // Cornell International Law Journal, 1993. - 26: 1-58.
12. Abbott K. International Relations Theory, International Law and the Regime Governing Atrocities in Internal Conflicts // American Journal of International Law, 1999. - Vol. 93 (2): 361-379.

13. Abbott K. Modern International Relations Theory: A Prospectus for International Lawyers // Yale Journal of International Law. 1989. - 14: 335-411.

14. Abbott K. The Trading Nation's Dilemma: The Functions of the Law of International Trade // Harvard International Law Journal, 1985. - 26: 501-532.

15. Abbott K. Toward a Richer Institutionalism for International Law and Policy // Journal of International Law and International Relations, 2006. - 1: 9.

16. Aceves W. Institutionalist Theory and International Legal Scholarship // American University Journal of International Law, 1997. - 12 (2): 227-266.

17. Armstrong D., Farrell Th., Lambert H. International Law and International Relations. - Cambridge: Cambridge University Press, 2007.

18. Ayaz Sh. A Theoretic Approach to Transnational Terrorism // Georgetown Law Journal, 1992. - Vol. 80: 2131-2174.

19. Benvenisti E. Collective Action in the Utilization of Shared Freshwater: The Challenges of International Water Resources Law // American Journal of International Law, 1996. - 90: 384-415

20. Biersteker T., Spiro P., Sriram Ch., Raffo V., eds. International Law and International Relations: Bridging Theory and Practice. - London: Routledge, 2007.

21. Brewster R. Rule-Based Dispute Resolution in International Trade Law. Virginia Law Review, 2006. 92: 251-288.

22. Brunnée J., Toope S. Environmental Security and Freshwater Resources: Ecosystem Regime Building // American Journal of International Law. 1997. - 91: 26-59.

23. Bueno de Mesquito B., Smith A. The Pernicious Consequences of UN Security Council Membership // Journal of Conflict Resolution, 2010. - Vol. 54 (5): 667-686.

24. Byers M. Taking the Law out of International Law: A Critique of the Iterative Perspective // Harvard International Law Journal. 1997. - 38: 201-205.

25. Chayes A., Chayes A. On Compliance // International Organization, 1993. - 47: 175-205.

26. Chayes A., Chayes A. The New Sovereignty: Compliance with International Regulatory Agreements. - Cambridge, Mass.: Harvard University Press, 1995.

27. Colburn J. Note, Turbot Wars: Straddling Stocks, Regime Theory, and a New U.N. Agreement // Florida 
DOI: $10.7256 / 1811-9018.2014 .8 .7539$

При цитировании этой статьи сноска на doi обязательна

Международное право в XXI веке

State University Journal of Transnational Law \& Policy, 1997. - 6: 323-366.

28. Colombatto E., Macey J. A Public Choice Model of International Economic Cooperation and the Decline of the Nation State // Cardozo Law Review, 1996. - 18: 925-956.

29. Downs G., Rocke D., Barsoom P. The Transformational Model of International Regime Design: Triumph of Hope or Experience? // Columbia Journal of Transnational Law, 2000. - 38: 465-514.

30. Fidler D. Mission Impossible? International Law and Infectious Diseases // Temple International and Comparative Law Journal, 1996. - 10: 493-502.

31. Ginsburg T., McAdams R. Adjudicating in Anarchy: An Expressive Theory of International Dispute Resolution. William and Mary Law Review, 2004. 45: 1229-1339.

32. Goldsmith J., Posner E. A Theory of Customary International Law. University of Chicago Law Review, 1999. 66: 1113-1177.

33. Goldsmith J., Posner E. The Limits of International Law. Okhford University Press, 2005.

34. Goldsmith J., Posner E. Understanding the Resemblance between Modern and Traditional Customary International Law. Virginia Journal of International Law, 2000. 40: 639-672.

35. Goldstein J., Kahler M., Keohane R., Slaughter A. M., eds. Legalization and World Politics. - Cambridge: MIT Press, 2001.

36. Hafner-Burton E., Victor D., Lupu Y. Political Science Research on International Law: The State of the Field // American Journal of International Law, 2012. - Vol. 106, No. 1: 47-97.

37. Hathaway O. Do Human Rights Treaties Make a Difference? Yale Law Journal, 2002. 111: 1935-2042.

38. Hathaway O., Koh H., eds. Foundations of International Law and Politics. - New York: Foundation Press, 2005.

39. Hirsch M. The Future Negotiations over Jerusalem, Strategical Factors and Game Theory // Catholic University Law Review, 1996. - 45: 699-722;

40. Keohane R. After Hegemony: Cooperation and Discord in the World Political Economy. - Princeton University Press, 1984.

41. Keohane R. International Relations and International Law: Two Optics // Harvard International Law Journal, 1997. - 38: 487-502.

42. Koremenos B. Contracting around International Uncertainty. American Political Science Review, 2005. 99: 549-565.

43. Koremenos B. If Only Half of International Agreements Have Dispute Resolution Provisions, Which Half
Needs Explaining? // Journal of Legal Studies, 2007. - 36: 189-212.

44. Koremenos B. Loosening the Ties That Bind: A Learning Model of Agreement Flexibility. International Organization, 2001. 55: 289-325.

45. Koremenos B. When, What, and Why Do States Choose to Delegate?.// Law and Contemporary Problems, 2008. - Vol. 71 (1): 151-192.

46. Koremenos B., Lipson Ch., Snidal D. The Rational Design of International Institutions // International Organization, 2001. - 55 (4): 761-799.

47. Legalization and World Politics (Special Issue) // International Organization. - 2000. - Vol. 54, No 3.

48. Macey J. Chicken Wars as a Prisoner's Dilemma: What's in a Game? // Notre Dame Law Review, 1989. - 64: 447450 (review of Conybeare J., Trade Wars: The Theory and Practice of International Commercial Rivalry)

49. Mitchell R. Regime Design Matters: International Oil Pollution and Treaty Compliance // International Organization, 1994. - Vol. 48 (3): 425-458.

50. Mock W. Game Theory, Signaling and International Legal Regulations // George Washington Journal of International Law \& Economics, 1992. - 26: 33-66.

51. Montana-Mora M. International Law and International Relations Cheek to Cheek: An International Law/ International Relations Perspective on the US/ EC Agricultural Export Subsidies Dispute // North Carolina Journal of International Law and Commercial Regulation, 1993. - 19: 1.

52. Plotkin B. Mission Possible: The Future of the International Health Regulations // Florida State University Journal of Transnational Law \& Policy, 1997. - 6: 503.

53. Raustiala K. Form and Substance in International Agreements. American Journal of International Law, 2005. 99: 581-614.

54. Rochester M. Between Peril and Promise: The Politics of International Law - Washington, DC: CQ Press, 2006.

55. Schmidt R. International Negotiations Paralyzed by Domestic Politics: Two-Level Game Theory and the Problem of the Pacific Salmon Commission // Environmental Law, 1996. - 26: 95-139.

56. Scott R., Stephan P. The Limits of Leviathan: Contract Theory and the Enforcement of International Law. 2006. New York: Cambridge University Press.

57. Setear J. An Iterative Perspective on Treaties: A Synthesis of International Relations Theory and International Law // Harvard International Law Journal. 1996. - 37: 139-229. 
DOI: $10.7256 / 1811-9018.2014 .8 .7539$

При цитировании этой статьи сноска на dоі обязательна

\section{Право и политика $8(176) \cdot 2014$}

58. Setear J. Responses to Breach of a Treaty and Rationalist International Relations Theory: The Rules of Release and Remediation in the Law of Treaties and the Law of State Responsibility. Virginia Law Review, 1997. 83: 1-126.

59. Simmons B., Steinberg R., eds. International Law and International Relations. - New York: Cambridge University Press, 2006.

60. Slaughter A. - M. International Law and International Relations Theory: A Dual Agenda // American Journal of International Law. 1993. - 87: 205-239.

61. Slaughter A. - M. Liberal International Relations Theory and International Economic Law // American Journal of International Law, 1995. - 10: 717-731.

62. Slaughter A.-M., Tulumello A., Wood S. International Law and International Relations Theory: A New Generation of Interdisciplinary Scholarship // American Journal of International Law. 1998. - 92: 367-397.
63. Swaine E. Unsigning. Stanford Law Review, 2003. 55: 2061-2089.

64. Sykes A. Protectionism as a "Safeguard": A Positive Analysis of the GATT "Escape Clause" with Normative Speculations. University of Chicago Law Review, 1991. 58: 255-303.

65. Tsebelis G., Garrett G. Agenda Setting, Vetoes, and the EU's Codecision Procedure // Journal of Legislative Studies, 1997. - 3: 74-92.

66. Tsebelis G., Garrett G. The Institutional Determinants of Intergovernmentalism and Supranationalism in the EU // International Organization, 2001. - 55(2): 357-390.

67. Tsebelis G., Yataganas X. The Treaty of Nice, the Convention Proposal, and the Treaty Establishing a Constitution for Europe: A Veto Players Analysis // European Constitutional Law Review, 2005. - 1 (3): 429-451.

68. Waller S. Neo-Realism and the International Harmonization of Law: Lessons from Antitrust // University of Kansas Law Review, 1994. - 42: 557-604. 